\title{
Na biblioteca vaginal: un discurso amoroso
}

\author{
Cecily Marcus $^{1}$
}

\section{Apresentação dos tradutores}

COMO SE DOCUMENTA O QUE ESTÁ FALTANDO; DE QUE FORMA A HISTÓRIA PODE RELATAR O QUE NÃO DEIXA REGISTROS; será possível pensar a memória a partir de suas falhas? Cecily Marcus, professora da Universidade de Minnesota, lança essas e outras questões no artigo "Na biblioteca vaginal: um discurso amoroso", parte de sua pesquisa sobre cultura clandestina na ditadura argentina. Publicado originalmente na revista "Políticas de La Memoria", do Centro de Documentación e Investigación de la Cultura de Izquierda, em 2009, apresentam-se histórias de resistência à ditadura militar a partir da ausência de seus vestígios. Durante dois anos, a pesquisadora americana entrevistou mais de quarenta escritores, artistas, poetas, intelectuais, estudou cineclubes, grupos de poesia e de teatro de Buenos Aires, Rosário e Córdoba. É esse vasto material que dá corpo a um arquivo que se constitui enquanto lacuna.

A biblioteca vaginal, como sinaliza a autora, não é uma metáfora. Tratava-se de manuscritos que circulavam entre as presas políticas através de suas vaginas. Liderada por mulheres, essa prática clandestina ao mesmo tempo evidencia e coloca em xeque a predominância de uma cena masculina na linha de frente da resistência, ao trazer para a superfície a sua obs-cena. Se a maioria das revistas culturais de oposição à ditatura foi dirigida por homens, por exemplo, é preciso resgatar a memória dos subterrâneos comandados por mulheres e assim evitar o relato de uma história parcial.

Neste artigo, a biblioteca vaginal vai além de uma prática clandestina específica e vira dispositivo para se pensar movimentos de contracultura durante a última ditadura argentina. Pequenos, quase ínfimos, coletivos experimentais como o Teatro Cucaño, no entanto, foram capazes de intervir na esfera pública e permanecer na memória de seus conterrâneos. Os rastros e resíduos, as ruínas encontradas por Cecily Marcus ajudam a reconstituir a memória do que significaram para uma comunidade vítima da restrição dos regimes autoritários.

Vale lembrar que o contato com esse texto é mais um desdobramento de trabalhos realizados entre 2007 e 2014 na cidade de Rosário, num período do convênio internacional de pesquisa entre Brasil e Argentina CAPES-CAPG-SPU, posto em prática pelo Departamento de Letras da PUC-Rio e pela Universidade Nacional de Rosário (UNR). Nesse tempo, diversos pesquisadores docentes e discentes reinventavam o caminho de cooperação entre as humanidades sul-americanas, bastante enfraquecida pelos ventos do norte que pararam moinhos e trouxeram Condores e outros Cronópios bizarros.

O debate em torno da memória adquiriu uma importância fundamental nesse trânsito. Havia uma Argentina mais combativa em relação às políticas públicas para a memória, talvez fortalecida pela retomada democrática menos abrangente em termos de anistia, e um Brasil lutando pelo direito a uma comissão da verdade, à indenização de vítimas do regime autoritário e a novos dispositivos de acesso e registros dessa memória, não só como direito ao passado, mas sobretudo com a confiança de que a garantia desse direito é peça fundamental na articulação de ações afirmativas para um presente ampliado.

Dentre as diversas formas desse percurso, documentais e expressivas (suas escritas testemunhais, performáticas, sonoras, gráficas, burocráticas) essa tradução é um fragmento que pretende, ainda em 2020,

\footnotetext{
${ }^{1}$ Professora e curadora da biblioteca da Universidade de Minnesota, fundadora do banco de dados Umbra Search - African American History (www.umbrasearch.org). Contato: marc0082@umn.edu
} 
reforçar a necessidade de pensar a memória e as práticas contemporâneas de arquivo em sua dimensão política e poética; entre conservação e invenção.

\begin{abstract}
"Arca, desta vez em latim ("ark" em inglês) é o baú ou arca, a arca em madeira de acácia que abriga as tábuas de pedra; mas arca diz também o armário, o cercado, a cela da prisão, o reservatório." (Jacques Derrida) ${ }^{4}$
\end{abstract}

\title{
I. Na Biblioteca Vaginal
}

Quando Lina Capdevila tinha dezessete anos, ela foi presa em Rosário, a cidade em que nasceu. Foi acusada de portar materiais políticos subversivos: alguns eram livros, mas a maioria era de panfletos do partido trotskista onde militava desde a época do Ensino Médio. Buscando uma forma criativa e política de trabalhar, em uma cidade provinciana a quatro horas de Buenos Aires, a educação política de Capdevila começou com as atividades partidárias, incluindo as de um partido relativamente liberal como o Partido Socialista dos Trabalhadores. Mas a sua educação não terminou por aí. Em 1977 ela foi encarcerada na Estación de Policía de Rosario - uma prisão que funcionava como centro de detenção - e a partir daí começou um périplo por distintas prisões em que foi objeto de assédios e interrogatórios. Capdevila poderia ser a Forrest Gump argentina, por seu papel de testemunho da história: presente quando o golpe foi dado em 24 de março de 1976, presente diante dos torturadores mais notórios da ditadura e quando as Madres de la Plaza de Mayo começaram a marchar, presente quando a ditadura militar se desintegrou e os punks de cabelos em pé e roupas rasgadas começaram a brotar por toda Buenos Aires.

Conversando com Capdevila mais de vinte e quatro anos depois em um café em Rosário que havia funcionado como cenário de performances a cargo de adolescentes rosarinos durante a ditadura, ela comentou que foi no cárcere onde encontrou sua real educação política. Nas conversas, nos enfrentamentos e debates com outras prisioneiras Capdevila descobriu quais assuntos políticos realmente importavam para ela, quais desprezava e que tipo de curiosidades intelectuais poderiam mantê-la viva. Foi aí que começou a ser crítica da cultura dos partidos políticos que, por um lado, fomentavam capacitação intelectual, mas, por outro, condenavam interesses intelectuais $e$ criativos. Capdevila falou de brigas acaloradas entre as prisioneiras, em que as posições políticas e as ideias eram trocadas aos gritos. Suas companheiras de cela eram homofóbicas e pouco receptivas a ideias divergentes, e tão culturalmente conservadoras quanto politicamente radicais. Esses conflitos, no fim das contas, terminaram sendo profundamente renovadores para ela, que vinha de uma família de operários e cuja vida até aquele momento tinha sido dedicada ao bem-estar social e político dos mais necessitados e ignorados da Argentina. Na prisão, Capdevila e as outras prisioneiras se organizaram para continuar perseguindo interesses coletivos, e produziram jornais em miniatura que, incrivelmente, copiavam em papeis de cigarros, com notícias criadas a partir de rumores, testemunhos de visitas que ocasionalmente recebiam de fora e fantasias de uma existência mais livre. A forma que esses jornais tomaram - pequenos por necessidade, extremamente frágeis e definitivamente perecíveis - obrigou-as a escrever de tal modo que não

\footnotetext{
2 Bolsista do Programa Nacional de Pós-Doutorado/ CAPES no departamento de Letras da PUC-Rio. E-mail: alinelfbarbosa@gmail.com

${ }^{3}$ Professor do Departamento de Letras e no curso de Artes Cênicas da PUC-Rio. E-mail: dcastanheira@gmail.com

${ }^{4}$ DERRIDA, Jacques. Mal de arquivo: uma impressão freudiana. Tradução Claudia de Moraes Rego. Rio de Janeiro: Relume Dumará, 2001, p. 36.
} 
houvesse necessidade de revisão, sem cometer erros factuais ou de ortografia, numa escrita que fosse visivelmente legível.

Quando perguntei a Capdevila se algum desses jornais ainda existia, ela riu e me disse: "Claro que não. Não era possível tirá-los. Levávamos dentro". Nesse momento, não entendi o que quis dizer. Os escritos das mulheres que estiveram nos centros de detenção devem ter sido um tipo de prática de memória secreta que as permitiu manter contato com o mundo exterior e com um mundo de organização política em crise que já não existia. Tinham sido isso. Os jornais de prisão eram também parte de uma cadeia de peças informativas tomadas de outro recurso clandestino: os famosos caramelos ${ }^{5}$, já que era prática comum cultivar fontes de informação acerca do mundo que existia para além das paredes do cárcere, independentemente do tamanho do risco. Mas, a estranheza do comentário de Capdevila - o fato de que ela carregara dentro de si jornais feitos de papéis de cigarro - foi interpretada como mais um desses pontos cegos a que toda pesquisa da cultura clandestina da ditadura deve enfrentar. Tão emblemáticos como outros documentos desaparecidos, perdidos ou destruídos, estes jornais pareciam indicar que a história da vida intelectual da ditadura é feita de pistas incompletas, uma história que só pode ser recordada em fragmentos, nunca inteiramente recobrada.

Toda aproximação e análise do que aconteceu na cultura subterrânea ${ }^{6}$ da última ditadura estão baseadas em códigos secretos e silêncios, em indícios que nem sempre podem ser rastreados, em publicações que um dia surgiram e no dia seguinte deixaram de ser publicadas, sem aviso prévio ou sem rastros a seguir. Livros e papéis foram queimados ou enterrados. Até mesmo a coleção mais completa de documentos da vida subterrânea da última ditadura só pode ser considerada uma mostra representativa - algo que, dadas as circunstâncias quase impossíveis de preservação desses documentos, não é uma façanha menor. Se é certo que a cultura clandestina do período ditatorial não pode ser totalmente recuperada, isso não quer dizer que os recursos disponíveis careçam de profundidade, sutileza ou importância em tantos meios para ingressar no mundo da resistência cultural, um mundo do qual, sim, é possível falar, é possível documentar e entender. Um mundo que inclui o caráter extremo - de abjeção - da relação entre mulheres, homens e resistência, e os incríveis atos de imaginação e sobrevivência que marcaram suas vidas durante a ditadura. O comentário de Capdevila - indireto e sem maiores explicações - foi uma porta de entrada à biblioteca vaginal.

A biblioteca vaginal não é uma metáfora. Tal como Capdevila finalmente explicou, as mulheres nas prisões da ditadura escreveram, leram e fizeram circular jornais clandestinos e livros que previamente haviam copiado de forma meticulosa em papéis de cigarros e que guardavam em suas vaginas para compartilhar mais tarde entre elas. Leram O Capital, romances argentinos e europeus, e os jornais que elas mesmas faziam. Todos eram literalmente levados internamente até que os frágeis arranjos se deterioravam pelo uso, pela sujeira dos dedos ou pela umidade das vaginas.

Feita e conduzida por mulheres, a biblioteca vaginal foi uma resistência encarnada à tirania da ditadura. Também foi um exemplo de como as diferenças sectárias em questões políticas foram abandonadas para favorecer a comunicação entre prisioneiras, o produto de uma condição compartilhada que exigiu a superação de toda diferença política - em termos de afinidades e de interesses culturais, de idade, de educação, experiência e de passado. A biblioteca vaginal, tal como foi erigida entre as paredes das prisões, teve origem sem uma comunidade de homens, o que a faz atípica em relação à maioria das formas de resistência cultural que aconteceram antes e durante a ditadura.

\footnotetext{
${ }^{5}$ Os caramelos eram documentos, mensagens e relatórios escritos pelas prisioneiras em caligrafia milimétrica em papéis enrolados ou dobrados e embrulhados em camadas sucessivas de plástico a fim de contornar o cerco informativo. Esses arquivos destinados às visitas externas eram carregados na boca e, em caso de revista surpresa, engolidos (N.T.).

${ }^{6}$ Escolhemos, na tradução, manter o termo "cultura subterrânea", como no original, nas vezes em que aparece no texto. No entanto, seria possível traduzi-lo também por cultura underground ou contracultura (N.T.).
} 
É certo que, como militantes políticas, as mulheres representaram um papel-chave nas atividades dos partidos e nas organizações prévias à ditadura, mas geralmente ocuparam cargos secundários e de apoio em lugar de cargos de direção. Uma vez que muitas das atividades políticas na Argentina surgiram a partir de sindicatos e de organizações de trabalhadores, foi comum para as mulheres serem tratadas - e inclusive tratarem a si mesmas - como seguidoras da liderança dos homens, ainda que existam exceções significativas a esse respeito. O feminismo moderno, como marco explícito de ação social, não teve plenitude na Argentina até depois da ditadura - quando vários grupos de mulheres e as publicações de que faziam parte começaram a assumir protagonismo ao repensar a história das mulheres na vida cotidiana e política do país, realizando pesquisas que incluíam desde questões de gênero no ambiente doméstico até direitos reprodutivos e relações de trabalho (domésticas e não domésticas).

Mas o fato é que, durante a ditadura, a maioria dos grupos da cultura subterrânea foi dirigida por homens. Das mais de setenta revistas culturais publicadas durante esse regime, que formam parte dos arquivos do CeDInCI (Centro de Documentación e Investigación de la Cultura de Izquierda) ${ }^{7}$, somente duas têm mulheres como diretoras, e muito mais homens do que mulheres aparecem como autores nessas revistas. Beatriz Sarlo, ainda hoje diretora da Punto de Vista, tal como era no primeiro número de 1978, é a exceção mais conhecida. A história de Punto de Vista é, de certo modo, crucial para entender a biblioteca vaginal, uma parte dessa grande história dos papéis que, às vezes visíveis e outras vezes escondidos, as mulheres tiveram na resistência.

Punto de Vista é parte da biblioteca vaginal se a biblioteca vaginal é entendida como um arquivo que só pode ser recobrado parcialmente, uma biblioteca feita dos vestígios do que ocorreu nos subterrâneos. Mas esse é apenas um aspecto da biblioteca vaginal, porque, ao ter sido produzida nas piores prisões clandestinas da ditadura, ela é ao mesmo tempo um arquivo que já não existe, uma vez que não deixa muito para ser lido no futuro - é um arquivo que não tem domicílio e que, portanto, também não tem um lugar que possa ser visitado por acadêmicos, estudantes ou historiadores. Como tal, a biblioteca vaginal é um desafio não somente para a ideia de biblioteca como instituição que produz o passado e serve ao futuro, senão também para as muitas práticas de memória e de recuperação que se ocupam das catástrofes. Sem nada para colecionar, sem papéis para verificar, e, frequentemente, sem testemunhos ou sobreviventes para entrevistar, é tanto uma biblioteca em prisão domiciliar quanto uma biblioteca sem domicílio. Tal como escreve Jacques Derrida, em Mal de arquivo, a respeito da pulsão arquiviolítica, a biblioteca vaginal "não deixa nenhum monumento, não deixa como legado nenhum documento que lhe seja próprio".

A biblioteca vaginal - um arquivo que nunca vai além do clandestino e do secreto, e que é a encarnação da relação mais íntima de uma mulher consigo mesma - é o arquivo no pior caso. Além das características materiais do arquivo, a biblioteca vaginal é definida pela natureza do seu conteúdo - os tipos de mensagens e comunicações que foram copiados em papéis de cigarros para serem compartilhados entre presas com várias afinidades políticas e com o objetivo comum de sobreviver. A sobrevivência entre as paredes das prisões clandestinas da ditadura incluiu mais do que a sobrevivência do pensamento e da imaginação que caracterizaram o sem-número de grupos culturais subterrâneos que tiveram como propósito a defesa da liberdade de imaginação. A sobrevivência nas entranhas mesmo da ditadura foi mais básica e talvez mais criativa também. As usuárias da biblioteca vaginal traficaram um discurso amoroso, no sentido que Roland Barthes deu à expressão: uma conversa íntima feita do marginal e do impróprio; o intercâmbio de comunicações entre indivíduos que, mesmo estranhos entre si, se sentiram incontornavelmente compelidos a falar uma linguagem secreta e

\footnotetext{
7 CeDInCI é um centro de documentação (biblioteca, hemeroteca e arquivo) dedicado à recuperação, preservação, conservação, catalogação e divulgação das produções políticas e culturais da esquerda latino-americana, desde suas origens na segunda metade do século XIX até os dias atuais.

${ }^{8}$ DerRidA, Jacques. Mal de arquivo: uma impressão freudiana. Tradução Claudia de Moraes Rego. Rio de Janeiro: Relume Dumará, 2001, p. 22.
} 
clandestina que talvez não pudesse ser totalmente decodificada. Na biblioteca vaginal, as conversas escritas foram produto do cativeiro físico, mas também do cativeiro de ideias e de identidades que haviam sido previamente impostas e, ao mesmo tempo, cultivadas e protegidas pelas próprias prisioneiras.

Enquanto comunicação do desamparo, o discurso amoroso de Roland Barthes é a linguagem dos ignorados, dos desacreditados e menosprezados - uma linguagem que resiste aos mecanismos de autoridade e se empenha em sua própria existência. Enquanto discurso de profunda solidão, o discurso amoroso é uma linguagem em exílio, uma linguagem sem domicílio, angustiada e sem-fim, uma linguagem que, de todos os modos, busca, insistentemente, o outro. Enquanto discurso de explosões verbais e declarações impróprias, tanto a comunicação entre os amantes (que, de acordo com Barthes, quase não podem se comunicar ou ser entendidos entre si) como a comunicação na biblioteca vaginal são linguagens polissêmicas que demandam interpretação constante. Barthes escreve que o discurso amoroso é a trapaça de uma linguagem que esculpe a sua própria existência em um mundo que não oferece nada resolvido. Ao falar dos primeiros anos de Punto de Vista, Beatriz Sarlo comentou:

Para nós, em condição de ditadura, tudo tinha uma espécie de valor simbólico, e essa condição impõe, aos que tentam uma resistência, as mesmas condições que Barthes descreve para o amante em Fragmentos de um Discurso Amoroso. Ele diz: para o amante, tudo é signo; e eu diria: para o resistente tudo é signo, às vezes, de maneira muito exagerada. Ele é um alegorista, como a velha fórmula marxista-leninista que chamava a esse discurso "esópico", pelas fábulas de Esopo. Então, eu me lembro de que, para nós, tudo era signo, em tudo pensávamos que estávamos significando. Nós pensávamos que um senhor que saía de um quarto escuro, ou que abria a porta a um quarto escuro, por exemplo, já estava significando. Claro que quase ninguém podia perceber isso; me lembro de comentar com o diagramador: abrir a caixa preta que é a ditadura [...] Evidentemente que ninguém podia se dar conta isso, era bem mais a substância de que nos alimentávamos. Isto era para os que fazíamos a revista, tinha um caráter fortemente simbólico e alegórico, mas que era como o discurso do amor para o amante, tudo era signo para o amante, mas não para o restante do mundo ${ }^{9}$.

Do pensamento de Derrida sobre arquivo aos conceitos de Barthes relacionados ao discurso amoroso, o trabalho da biblioteca vaginal pode ser pensado como uma prática ao mesmo tempo aprisionada e libertadora. Representa uma contínua luta de restrição e de resistência à restrição. O trabalho da biblioteca vaginal se desprende das práticas das prisioneiras, seu alcance vai mais além dessas mulheres e se estende a todos os tipos de resistência cultural que estavam acontecendo sob as condições mais adversas durante a ditadura. Na biblioteca vaginal, encontramos os adolescentes do Teatro Cucaño, um pequeno grupo experimental da cidade de Rosário, ao mesmo tempo que os reconhecidos intelectuais da Punto de Vista. Homens e mulheres, ainda que majoritariamente homens, que trabalharam para documentar e refletir sobre um período de terror e extremismo através de atos criativos e intelectuais que geralmente não encontraram uma audiência fora do ambiente hermético e improvável da biblioteca vaginal.

Os artefatos que sobreviveram à biblioteca vaginal podem ser encontrados em armários, sótãos, porões e nos arquivos do CeDInCI. As revistas culturais subterrâneas editadas na última ditadura - revistas pequenas, em muitos casos feitas por jovens argentinos, às vezes com impressão ruim, e geralmente de publicação irregular -

\footnotetext{
${ }^{9}$ Entrevista com a autora, em Buenos Aires, 16 de outubro de 2002.
} 
documentam um impulso vital durante uma época aterrorizante. Em condições excepcionais, comunidades de escritores, intelectuais e artistas - comunidades destruídas pela violência do estado de terror - mantiveram a tradição da cultura literária argentina e, ainda, criaram uma forma de historiografia que registrava os eventos que eram negados e apagados do registro oficial. Estas revistas, desde Punto de Vista até revistas mais subterrâneas como Ulises, Boletín Alternativo, Propuesta para la Juventud, Subterráneo, Germinal e a surrealista Poddema - são exemplos de reportagem no sentido mais profundo: estas revistas põem em dúvida, simultaneamente, os mesmos eventos e as ideias que dão à luz de maneira furtiva. Na procura constante por alcançar os limites do possível, estes escritores encontraram métodos alternativos para realizar e desenvolver suas reuniões, debater suas agendas políticas, suas filosofias literárias, sua forma de escrever e de existir. Em cada reunião e em cada frase publicada - ainda que extremamente oblíqua e indireta -, corria-se o risco da traição do coletivo, e, além disso, da auto-traição. Por isso, cada uma dessas frases e cada palavra exigia uma elaboração minuciosa. As diversas proibições da época, plasmadas em censura e autocensura, transformaram as conversas públicas compartilhadas por aquelas revistas no desafio do discurso regulado e da memória histórica coletiva. As revistas tiveram origem justamente neste ponto, onde as técnicas literárias de mais alto nível se chocavam com uma situação política cada vez mais grave.

Durante o primeiro ano da ditadura, muitas publicações deixaram de ser editadas. Mas, já no ano de 1977, novas propostas começaram a substituir as anteriores. Em 1979, uma associação de revistas culturais independentes chamada ARCA (Asociación de Revistas Culturales Argentinas) foi fundada em Buenos Aires por jovens escritores - quase todos nos seus vinte anos, que se reuniam na Casona de Iván Grondona ${ }^{10}$, na rua Corrientes com a rua Montevideo -, reunindo oitenta e cinco publicações iniciadas depois da ditadura ${ }^{11}$. Houve inclusive algumas revistas que fecharam antes para reinventar-se, gerando uma relação de continuidade com projetos anteriores: Escarabajo de Oro (a revista de Abelardo Castillo e Liliana Heker, fechada em 1974) e Los Libros (de Beatriz Sarlo, Carlos Altamirano e Ricardo Piglia, fechada em fevereiro de 1976) antecedem as revistas Ornitorrinco (1977) e Punto de Vista (1978), respectivamente. E, enquanto algumas publicações estavam vinculadas superficialmente a partidos políticos (Contexto ao Partido Comunista, Nudos aos maoístas do PCR, Cuadernos del Camino e Propuesta para la Juventud, ambas ao PST), outras se identificavam como publicações culturais independentes.

A cultura literária difundida nas revistas editadas durante a ditadura foi a continuação e, ao mesmo tempo, a ruptura de uma tradição. As revistas menores, independentes e subterrâneas, com antecedentes nas publicações de rock, deram nova dimensão à produção cultural argentina. Gente jovem com paixões e interesses intelectuais em seu ponto de formação no momento do golpe - indivíduos que não se consideravam nem escritores nem intelectuais - viam esse tipo de revista como uma forma rápida, relativamente barata, irregular, uma maneira quase acidental de difundir a sua expressão. Com apoio financeiro precário, algumas revistas utilizavam o mimeógrafo como modo de impressão, grampeando manualmente, enquanto outras tinham uma apresentação mais profissional. Desde as publicações das escolas secundaristas até as revistas vanguardistas, as realistas, as surrealistas e as roqueiras, há em quase todas elas um cuidado notável. É surpreendente a falta de erros ortográficos ou tipográficos. Talvez esse dado dê conta do cuidadoso processo de leitura e de releitura de cada novo artigo, diante de cada frase a ser publicada. Às vezes escritas à mão, muitas vezes impressas

\footnotetext{
${ }^{10}$ Ivan Grondona foi um ator argentino que instalou em sua casa uma livraria chamada La Casona de Ivan Grandona, onde havia reuniões para leitura de poesia, prosa, teatro, entre outras atividades (N.T.).

${ }^{11}$ Entre elas: Nova Arte (1978-1980), diretor: Enrique Zattara; Arte y Cultura (1978-1979), diretor: Miguel A. Ferreira; Cuadernos del Camino (1979-1980), diretora: Mónica Guistina; Expreso Imaginario (1976-1983), diretor: Jorge Pistocchi; Ayesha (ano desconhecido), diretor: Alejandro Margulis; Ulises (1978-1980), diretor: Horacio Tarcus; Suburbio, diretores: Antonio J. González e Horacio Ramos, entre outras.
} 
artesanalmente e logo distribuídas pessoalmente, essas revistas se diferenciavam em questões de forma, de ênfase, humor e de extensão. Para muitas publicações, o primeiro número foi o último. No entanto, quase todas elas possuíam um editorial de boas-vindas e de apresentação que era, ademais, um pequeno manifesto sobre o papel da revista durante esse tempo de emergência cultural. Seus editoriais concluíam com a frase hasta la próxima, uma expressão de esperança mais do que uma promessa.

Os artigos misturavam militância, crítica e práxis política com crítica e análise estética, apresentando uma insólita variedade de temas e de enfoques entre as distintas publicações assim como em uma mesma edição. Exemplos dessa afirmação são artigos como "Que pasa en el cine nacional?" (Boletín Alternativo, no.2, 1978) e "El boom de la cultura en la España sin Franco" (Contexto, no.1, janeiro de 1977); contos inéditos como "Los que se van", de Enrique Wernicke, escrito em 1957, que conta a história do desaparecimento de um grupo de amigos (foi publicado em Aparte de Punto, no.1, setembro de 1979 e logo em Brechas, no.3, novembro de 1982); entrevistas com gente como Luis Gregorich de La Opinión, o ator Pepe Soriano e outras figuras da cultura oficial; além de diversos ensaios sobre a relação entre a arte, a intelectualidade e a cultura. Uma revista como Contexto, publicação oficial do Partido Comunista, encenava a situação de o governo militar ser um governo legítimo com que se poderia dialogar. Chamava o general Jorge Rafael Videla de "Senhor Presidente" e convocava estrategicamente a junta militar para levantar uma espécie de discussão entre o governo e a revista, como se a discussão verdadeira fosse possível e inclusive facilitada pelos próprios militares. Outras revistas desenvolveram a linguagem de denúncia.

Para os escritores, os intelectuais e muitos dos jovens, as revistas eram uma tentativa de criar um campo coletivo de discussão, de enfrentar as inquietações desse momento e de "declarar que uma tradição cultural não estava morta”, como disse Horacio Tarcus. Sobre a experiência da revista cultural Ulises, que dirigia quando tinha em torno de vinte anos, Tarcus contou: "Nós dizíamos: seguimos em frente. Começamos de novo. Continuamos $^{12}$ ". Uma vez que a censura nem sempre apresentava uma lista de proibições explícitas ou completas, a escrita se transformava em oportunidade para a experimentação de sua própria linguagem criativa e política. O crítico Carlos Brocato, cofundador e codiretor das edições La Rosa Blindada - aliás, codiretor da revista que tinha sido publicada com esse nome entre 1962 e 1965 - chamou o gênero de revistas subterrâneas daquela época de "resistência molecular" e o descreveu como uma tentativa de "reconstituir espaços do tecido social fragmentado ${ }^{13}$. Nesses espaços da cultura - espaços esquecidos e abandonados - as revistas da época da ditadura revelam um mundo contraditório ainda que vital.

Em um editorial de 1980 que anuncia a colaboração das revistas Nova Arte (seis números em três anos) e Ulises (três números desde 1978), os dois jovens diretores se perguntam como se explica a multiplicação desse tipo de publicação num período de crise econômica, política e cultural. Tarcus, da Ulises, e Enrique Zattara, da Nova Arte, escrevem em "Hacia una gran revista cultural independiente":

Por que aparecem tantas revistas se a situação é asfixiante? Por que, nos
momentos em que mais se restringem os meios de expressão, mais necessários
eles se fazem? As revistas são a expressão da crise, mas também a sua negação.
Suas deficiências (impressão ruim, falta de regularidade, lacunas) são a
expressão da crise; por sua vez os seus sucessos (começando por sua própria
existência) são a negação ${ }^{14}$.

Esta declaração corajosa e dialética insiste em que as revistas da época da ditadura conviviam com uma realidade que buscava a sua destruição. Tarcus e Zattara, porém, anunciavam que não triunfaria uma visão

\footnotetext{
${ }^{12}$ Conversa da autora com Horacio Tarcus, Buenos Aires, 20 de abril de 2002.

${ }^{13}$ Brocato, Carlos. El exilio es el nuestro. Buenos Aires: Sudamericana; Planeta, 1986, p. 162.

${ }^{14}$ TARCUS, Horacio; ZATTARA, Enrique. Hacia una gran revista cultural independiente. Nova Arte, n. 6, 1980 , p. 36.
} 
totalizadora do mundo que não permitisse perspectivas múltiplas. O governo militar, que queria castigar e apagar as raízes da transformação social, não seria capaz de impedir os interstícios onde estes mesmos impulsos transformadores se fomentavam.

Irrevogavelmente ligadas às condições econômico-político-morais de sua época, as revistas publicadas durante a ditadura são mais do que a pura consequência sociológica ou a simples reação a forças mais poderosas que as suas. São aparições em geral efêmeras, mas com um caráter muito particular que não corresponde às expectativas sociais. Há quem diga que é impossível descrever a realidade de uma situação no momento em que ocorre. No ensaio $O$ narrador, ao tratar dos jovens soldados da primeira guerra mundial, o crítico Walter Benjamin diz que, entre os que deveriam ser capazes de narrar a realidade de um evento - um evento especialmente traumático - há, contraditoriamente, ainda mais silêncios, pois são eles que sofrem o empobrecimento de histórias e de experiências. As testemunhas que estiveram presentes por vezes nada tem para contar, enquanto os que não estiveram ficam obcecados com esse passado e com a construção da verdadeira versão do que aconteceu em sua ausência. As revistas da época da ditadura figuram e não figuram nessas visões da memória histórica e coletiva. Por um lado, são documentos performativos que atestam o que ocorreu documentam a história de seu próprio presente. A visão do futuro e a expectativa da duração da ditadura, por exemplo, podem ser lidas na forma que assumiram as revistas culturais: como muitos pensavam que a ditadura ia durar bastante, os jovens escritores se dedicavam mais a projetos que exigiam tempo e duração - os estudos filosóficos e estéticos - do que à militância política organizada. Mas, nas revistas também se encontram os mesmos silêncios que caracterizaram os anos da ditadura: nenhuma fala diretamente da tortura, dos desaparecidos ou de outros aspectos do estado de terror. Essas publicações são, por vezes, funcionais à mitificação da realidade, mas, ao mesmo tempo, confrontam-se com ela. Pode-se ler no editorial do segundo número de Cuadernos del Camino, do ano de 1980:

Nos dói e nos revolta que um dos slogans do Uruguai seja: "Venga a ver las películas que nunca verá en Buenos Aires". Nos dói e nos revolta tudo o que se deixa de pensar e de acreditar devido à cruel consequência dessa situação: a autocensura ${ }^{15}$.

Entre a declaração explícita e o que não pode ser comunicado há uma perda inevitável de pensamento. Isso é o que declara o editorial de Cuadernos del Camino - que a representação mais completa da verdadeira vida sob as condições da ditadura ia apresentar-se tanto no dito como no não dito, no escrito, no pensado. Os espaços negativos - os silêncios - também falam. Eduardo Galeano, quando encerrou a revista Crisis ${ }^{16}$, em julho de 1976, disse: "Cuando las palavras no pueden ser más dignas que el silencio, más vale callarse ${ }^{17}$.

\section{La cucaracha na biblioteca vaginal:}

\section{o Teatro Cucaño, Rosário, 1980}

Rosário, Argentina, é onde teve início a biblioteca vaginal, uma cidade de pontos mortos - fábricas falidas, prédios em ruínas, ruas que terminam nos princípios verdes da pampa argentina e grupos políticos que foram rápida e completamente destruídos pelas forças da ditadura. Vivendo em uma cidade de poucas saídas e em um país que fechava cada uma de suas portas para o mundo exterior, um pequeno grupo de adolescentes de

\footnotetext{
${ }^{15}$ Editorial, em Cuadernos del Camino, n. 2, 1980, p. 3.

${ }^{16}$ Crisis foi uma revista política e cultural editada em Buenos Aires, entre maio de 1973 e agosto de 1976. Seu diretor foi o escritor uruguaio Eduardo Galeano. Existiu uma rápida segunda etapa desta revista (de 1986 até 1987) (N.T).

${ }^{17}$ Galeano, Eduardo. Crisis, o cómo matar una revista, em Argentina: cómo matar la cultura. Madrid: Revolución, 1981 , p. 77.
} 
Rosário se viu dentro de uma biblioteca vaginal e tentou encontrar uma saída. Esses adolescentes usaram as poucas ferramentas e os parcos recursos que tinham disponíveis para, no processo de expressar ansiedade e frustração, produzir um discurso amoroso de que Barthes se orgulharia.

Não importa se eles interpretaram suas ações como um discurso amoroso (como Barthes talvez o tivesse feito) ou como um discurso raivoso feito de segredos (como eles talvez pudessem fazer) ou como uma coleção aleatória de palavras e de frases que por vezes comunicaram mais imaturidade do que resistência pontual (como certamente eles poderiam dizer), mas a linguagem inventada por esse grupo cultural chamado Teatro Cucaño é o melhor exemplo do que foi a biblioteca vaginal: pelas formas que assumiu, pelas pessoas que participaram e pelo uso que foi feito. Foi uma linguagem que por vezes cedeu sob o peso de sua época, que, ocasionalmente, assumiu a forma de explosões de humor tão efêmeras que até mesmo falar repetidamente sobre elas parece trair o significado dessa transitoriedade.

Muito do que o Teatro Cucaño fez - suas performances teatrais, que foram chamadas de "intervenções", ou as cartas que escreveram, ou os quadrinhos que imprimiram nas poucas edições de suas revistas - pretendia questionar a normalidade da vida cotidiana, fazer com que as pessoas parassem por um instante para pensar no que estava acontecendo. Tanto para o Teatro Cucaño quanto para os amantes de que fala Barthes, as comunicações foram usadas para produzir perguntas e confusão, para mostrar que nem tudo estava normal e que algo estava acontecendo - mesmo sem dizer o que efetivamente estava acontecendo.

Carlos Ghioldi cursava o Ensino Médio durante o golpe de 1976. Ele tinha quinze anos e se envolveu com o Partido Socialista dos Trabalhadores, interessado casualmente em arte e um fã do rock and roll norteamericano e argentino. Com o início da ditadura, tudo o que Ghioldi achava interessante foi proibido explícita ou implicitamente, deixando a ele e a seu grupo de amigos pouco a fazer além dos limites sufocantes do colégio. Ghioldi morava com a mãe em um bairro da classe operária. O irmão mais velho vivia em Buenos Aires, fato que foi crucial na formação do Teatro Cucaño. Nos primeiros anos da ditadura em Rosário, diz Ghioldi, tudo o que ele e os seus amigos queriam fazer era impossível ou ilegal. "Tudo o que era diferente foi condenado como subversivo", me disse ele em um café em Rosário em 2002. Falando com uma incredulidade que ainda se mantém, ele continuou:

Tudo era proibido, inclusive que as mulheres usassem calças brancas. Ter cabelos compridos era uma ofensa séria. Tantas coisas eram proibidas, hoje é difícil imaginar. Não faz sentido agora - que você possa ser preso por ter cabelos compridos ou por beijar a sua namorada em público. O controle que o regime tinha sobre a sociedade era profundo ${ }^{18}$.

Depois das aulas, Ghioldi passava as tardes em casa com alguns poucos amigos, ouvindo e tocando música, embora nenhum deles soubesse realmente tocar instrumentos e apenas alguns pudessem ler partitura. A casa logo se tornou o ponto de encontro oficial de um grupo de cultura não oficial: quatro ou cinco adolescentes (nenhum com idade superior a dezessete) que ouviam discos de rock e passaram a recolher as parcas economias daqueles que dispunham para ajudar amigos detidos. Em 1979, transformaram suas paixões autodidatas na fundação do Teatro Cucaño.

Ghioldi descreve a origem do grupo experimental e cultural (cujas atividades variaram de "intervenções" teatrais, música e quadrinhos até escrever diversos ensaios e manifestos sobre arte e artistas independentes) como o produto de uma inquietação política e artística suficientemente poderosa para cruzar as linhas políticas e de classe que existiam entre os jovens de Rosário. Esses adolescentes estavam mais do que entediados, mais do que assustados e mais do que angustiados pelas limitações impostas pela ditadura e pelo que se passava ao seu redor - as prisões, os sequestros e os rumores de tortura. Quando o Teatro Cucaño começou, não era um grupo

\footnotetext{
${ }^{18}$ Entrevista da autora, Rosário, Argentina, 31 de julho de 2002.
} 
com um objetivo comum claramente definido e coerente, mas um coletivo formado por rapazes pouco convencionais interessados no que fosse. Foram influenciados pelo surrealismo, por exemplo, mas também o repudiaram - porque, como disseram em sua revista Acha acha cucaracha, o surrealismo acabou naturalizando os tempos impossíveis que viviam fingindo criticá-los ${ }^{19}$. Ao contrário dos membros do Teatro de Investigaciones Teatrales de Buenos Aires [TIT], que inspiraram o Teatro Cucaño e com quem trocavam correspondência regularmente, os cucaños começaram por não querer ser surrealistas ou seguidores leais de Breton, Artaud, Brecht, ou quem quer que fosse. Escreveram que não herdaram nada de seus ancestrais aparentes, exceto a perspectiva de fazer o que eles não haviam conseguido. E assim um grupo de adolescentes declarou ser o Teatro Cucaño, tomando o nome de Kurt Vonnegut ${ }^{20}$ e adotando a barata, a praga pré-histórica que se recusa a morrer, como seu símbolo. Eles se declararam artistas independentes ativos em um movimento de arte independente. Prometeram estudar um tema por ao menos quatro horas por dia. Aprenderam por si mesmos a ler francês, a ler partitura e a tocar instrumentos. Estudaram Artaud, Breton e Brecht. Editaram revistas e escreveram longas cartas para ninguém em particular, relatando suas muitas falhas como um movimento artístico: sua incapacidade de concordar entre si, sua preguiça e falta de consistência, suas tentativas de nomear líderes apenas para descobrir que o restante do grupo resistia a seguir a liderança escolhida. Passaram mais tempo se criticando, em resumo, do que criticando seus tempos. Provavelmente passaram mais tempo tocando música do que estudando - mas também estudavam mais do que dormiam.

A primeira aparição pública do grupo ocorreu no início de 1979 - um show no Centro Cultural Catalán, local onde hoje funciona um café frequentado por estudantes e professores da Universidade de Rosário. Mas, como a maioria das performances do grupo, o show incluía mais do que o anunciado. O que tinham em mente não era tocar música para um público passivo, sentado para aplaudir como programado. Em vez disso, o Centro Catalán foi tomado de lixo, pouco menos do que destruído antes do início do evento. Não foi permitido aos participantes sentar ou ficar próximos um do outro e, no meio do centro cultural, os atores de Cucaño construíram um símbolo ignominioso da repressão ditatorial: um ponto de ônibus que chamaram de "zona de detenção", ironizando o duplo sentido da frase, devido à frequência com que muitos dos sequestros da época se davam quando se esperava o ônibus.

A performance daquela noite prenunciou o tipo de produção que caracterizaria o grupo nos anos seguintes. Essas performances do Teatro Cucaño, de acordo com as histórias que hoje são contadas - histórias que ainda circulam em Rosário como uma espécie de mitologia -, dispensaram muitas das convenções teatrais tradicionais. O público era de pessoas que estavam simplesmente na rua quando os cucaños apareciam, ou quem quer estivesse na igreja quando os cucaños atacavam. Atualmente, existe muito pouca documentação sobre esses eventos - algum panfleto antigo, uma pequena notícia publicada no jornal de Rosário, umas poucas fotos. Porém, assim como foram descritas por aqueles que eram membros do grupo, essas intervenções geralmente eram organizadas com o objetivo de alterar e confrontar os espaços públicos. Os atores, por exemplo, se encontravam durante o intervalo no principal teatro de Rosário e brigavam entre si. Era uma brincadeira simples, com o objetivo de interromper a aparente normalidade em um momento em que a história não era normal. Os cucaños podiam ser tão imprudentes quanto brincalhões, correndo o risco de ser detidos na entrada de um teatro por transformar um intervalo normal em um evento inteiro. Era uma afirmação de não pertencimento, dirigida a um meio definido por conduta adequada, privilégio de classe e cumplicidade com o

\footnotetext{
19 "Romper con todo lo que se ha hecho en el arte", en Teatro Cucaño Acha acha cucaracha no 0 (sem data), p. 2.

${ }^{20}$ Do romance Payasadas o nunca más solo, de Kurt Vonnegut (no original Slapstick or lonesome no more e, na edição brasileira, Pastelão ou solitário nunca mais), em que, na língua privada dos irmãos protagonistas cucaño significa cumpleaños (aniversário) (N.T.).
} 
terror do estado. Os transgressores eram expulsos do teatro não sem antes desferirem alguns golpes entre si. O Teatro Cucaño tratou de transformar a vida cotidiana em um conjunto de estranhos distúrbios.

Vários testemunhos concordam que sua intervenção mais bem-sucedida ocorreu em uma missa de domingo. Cinco ou seis dos cucaños foram à igreja. Fizeram o que se deve fazer nessas circunstâncias: vestiram-se adequadamente, entraram em silêncio e respeitosamente, sentaram-se e esperaram o início da missa. Quando isso aconteceu, um cucaño apontou um par de binóculos para o altar, como se colocasse os ritos cristãos sob um olhar microscópico. Outro cucaño entrou na igreja vestido em trapos e em cadeira de rodas, movendo-se desajeitadamente entre os bancos e as pessoas. Pedia esmolas em uma voz alta demais para uma igreja - mais alta que qualquer outra, com exceção de outro cucaño que, em um confessionário, contava com riqueza de detalhes o quanto vinha se masturbando ultimamente. Quando o padre ofereceu a comunhão, um dos cucaños tomou a hóstia, mas devolveu-a vomitando no padre uma mistura de café e folhas de mate que sua mãe havia preparado para a ocasião.

A intervenção na missa dominical não foi uma simples performance, mas uma interrupção total dos comportamentos normativos em uma das instituições mais reverenciadas pela ditadura e pelas pessoas cuja cumplicidade alimentou a existência do poder ditatorial. Era como se os meninos do Teatro Cucaño denunciassem a hipocrisia daqueles que rezavam e que, ao mesmo tempo, aprovavam as atrocidades do regime. Essa foi uma manhã positiva para os cucaños, não apenas porque denunciaram a ditadura e tudo o que ela representava, mas também porque interromperam a vida normal por pelo menos um momento. Sua intervenção foi ao mesmo tempo um ato de mau gosto de humor adolescente como um esforço para afirmar sua existência enquanto indivíduos que não estavam dispostos a sacrificar tudo para viver tranquila e confortavelmente. Se viviam tempos extremos: a arte que esse tempo exigia era uma arte combativa.

Em 1980, o Teatro Cucaño começou a trocar correspondência com o TIT (Taller de Investigación Teatral) de Buenos Aires, cujos membros haviam sido contatados através do irmão mais velho de Ghioldi e também por meio de Capdevila. Existem semelhanças impressionantes entre o Teatro Cucaño e o TIT de Buenos Aires, desde a sua capacidade de inovação desenfreada até o seu interesse cético, porém crescente, pelos surrealistas. Mas o TIT era um grupo maior e mais organizado, e a maioria de seus membros era mais velha do que seus colegas de Rosário. Uma diferença ainda mais importante tinha a ver com o grau de acesso que cada grupo tinha a interlocutores e professores, assim como a materiais de leitura. Os recursos intelectuais, artísticos e políticos do Teatro Cucaño eram significativamente mais limitados do que os do TIT e, como consequência, seu trabalho (suas intervenções, seus grupos de estudo e os escritos que produziam) era mais divertido e emocionalmente mais vívido do que o dos membros do TIT. De qualquer forma, oito meses após uma viagem ao Brasil para o festival de teatro "Alterarte" (também chamado de "Viajou sem Passaporte", como forma de evidenciar o status de exilados e de artistas em quase todo o Cone Sul), Carlos Ghioldi escreveu ao TIT afirmando que o Teatro Cucaño estava desmoronando devido ao seu isolamento e ao sentimento de frustração, incapaz de fazer mais do que desenvolver novos e mais complexos grupos de estudo:

Depois de meses de hermetismo e algumas horas depois de receber sua terceira carta [...] escrevemos, sob uma longa comitiva de desculpas. Apesar desse desespero que, na forma chamada Cucaño, continua entre seis ou sete cabeças que permanecem em Rosário, outras na Europa, alguns perdem o cabelo e emudecem no Sul [...] Fizemos e desfizemos alguns projetos, abrimos e fechamos instantaneamente nossas oficinas de transgressão ${ }^{22}$.

\footnotetext{
${ }^{21}$ Realizado, em 1981, nas dependências da Universidade de São Paulo (USP) e em outros espaços da cidade, com a participação de grupos de intervenção urbana de São Paulo e da Argentina, como o D’Magrela, o 3Nós3, o Teatro Cucaño, onTaller de Investigación Teatral, Taller de Investigación Cinematográficas e Musicales, entre outros (N.T).

${ }^{22}$ GHIOLDI, C. Carta a Compañeros del TIT. Arquivo Teatro Cucaño do CeDinCi, 4 may. 1982, p. 1.
} 
Ghioldi acrescentou que a tarefa com a qual o grupo estava ocupado naquele momento era a de designar um plano de estudo e de análise que pudesse "prestar especial atenção ao discurso epistemológico e à metodologia, confrontar a existência em sua relação prática e atividade de produção" ${ }^{23}$. Assim continuava a carta:

[Priorizamos] o aprofundamento de nossa tarefa investigativa em todos os campos do conhecimento e da sensibilidade dos homens, revolucionando-os para a sua capitalização futura. Trazendo a dialética a todas as ordens da vida - vida atual, abnegada, mutilada por miséria $^{24}$.

Exposto dessa maneira, o plano do Teatro Cucaño parece labiríntico, abstrato e tão desesperado quanto a abordagem de Ghioldi. É lido como se a combatividade explosiva das performances de rua do grupo tivesse sido substituída por um idealismo hermético aparentemente incapaz de alterar o que quer que fosse. O comentário de Ghioldi também mostra como o Teatro Cucaño entendia a história, o presente e o futuro. Ghioldi ou outro cucaño nunca escrevem sobre o passado, exceto em termos de desilusões a serem problematizadas no presente. E em nenhum lugar o futuro é mencionado mais do que com o objetivo de delinear planos de estudo que talvez nunca tenham se concretizado. Ao ler a prosa do Teatro Cucaño, nunca se pensa que os escritores se imaginassem portadores do conhecimento necessário para fazer previsões ou prescrever o futuro, e seus olhares para a história (a história do surrealismo, por exemplo) não parecem muito mais do que guias idiossincráticos de estudo a serem lidos por estudantes ávidos e basicamente autodidatas.

É como se os jovens do Teatro Cucaño tivessem uma concepção de tempo definida pela inefabilidade do momento, pela sensação do instante mesmo - aquele fragmento de tempo que pode desestabilizar o chão sob os pés e condená-lo a toda uma vida de sofrimento. Estavam muito pouco interessados em um futuro capaz de excluí-los da mesma maneira que o presente alienado e definido por outros. Por que se preocupar em pontificar sobre o futuro quando o presente nada fazia além de destruí-lo? Tudo o que os membros do Teatro Cucaño podiam fazer era roubar - livros, a atenção de um transeunte na rua, lembranças de escritores e artistas que viveram muito antes deles.

O fato de o Teatro Cucaño ter começado a existir sem a intenção de se tornar algo mais do que uma maneira criativa de se passar as tardes e acabado funcionando como uma tentativa séria de combater as restrições e agressões da ditadura, tem muito a ver com o plano de estudo e de trabalho intensivo de Ghioldi. Cada intervenção que planejaram - um número muito maior do que foram capazes de implementar - foi o produto de meses de discussão, debate, revisão, desacordo e planejamento. Entre os papéis que restam de Cucaño estão mapas, não apenas os oficiais de Rosário, mas os produzidos pelo próprio grupo. Espalhados entre esboços de cartas, fotografias e páginas de revistas, estão diagramas e cronogramas de ação, nomes de guerra e listas de membros e responsabilidades. O Teatro Cucaño tomou emprestada a sua organização dos trotskistas com os quais estavam familiarizados em seus círculos mais imediatos antes da ditadura. Observando os documentos que sobreviveram, entende-se por que os cucaños estavam interessados em estudar e planejar meticulosamente. Devido ao pequeno tamanho de Rosário e à força desproporcional dos militares e da polícia, cada incursão do Teatro Cucaño nas ruas rosarinas apresentava um grande risco.

As produções do Teatro Cucaño foram mais rumores do que obras de arte - quase todos os traços materiais desapareceram. A primeira foto de grupo mostra jovens ordenados usando máscaras, mas está superexposta a tal ponto que quase apaga os rostos daqueles que estão nela, tornando praticamente impossível a sua reprodução. O que resta, no entanto, é uma imagem deteriorada cujo estado consegue capturar o caráter efêmero e aleatório que caracterizou as atividades do grupo e o seu sentido. Os cucaños tomavam notas que

\footnotetext{
${ }^{23}$ Ibidem.

${ }^{24}$ Ibidem.
} 
geralmente destruíam ou que simplesmente perdiam. Não imprimiram panfletos antes da maioria de suas intervenções, preferindo o elemento surpresa a anunciar performances que poderiam ser canceladas, censuradas ou observadas de perto pela polícia (que produziu registros da existência do grupo, mas não mais que isso). $\mathrm{O}$ público de suas performances geralmente não se dava conta de seu caráter de espectador, muito menos quem ou o que estavam olhando. De fato, o Teatro Cucaño se apropriou da política do ver - e do não ver - que a própria ditadura tentara impor a muitos argentinos. A presença deles era furtiva e ostensiva ao mesmo tempo, da mesma maneira que os métodos de sequestro e de prisão na ditadura eram secretos e feitos para serem efetivamente vistos. Suas intervenções tentaram promover o ethos do "agora você vê, agora você não vê", para evidenciar que algo estava acontecendo. Talvez se tratasse de uma simples instalação de arte realizada por adolescentes. Talvez um estudante estivesse realmente sendo reprimido pela polícia.

Fazer isso, entretanto, em uma cidade onde a delegacia abrigava amigos, irmãs, irmãos, primeiros namorados e namoradas dos cucaños significava algo diferente do que simplesmente declarar que alguma coisa estava acontecendo. Envolvia, porém, o exercício de uma agenda invisível, embora palpável, não muito diferente das maquinações diárias de terror perpetradas pelas forças da ditadura. Por meio de suas intervenções, o Teatro Cucaño realizou operações de não ver e de esquecer que eram semelhantes ao controle que a ditadura exercia sobre os modos em que viviam ou sobreviviam diariamente. Suas intervenções pareciam sugerir que, assim como os atos de violência não refletiam na consciência das pessoas ou nos registros oficiais, eles também seriam esquecidos. Seus atos - estranhos, breves, abruptos demais - talvez também terminariam por não fazer parte da memória, da identidade e da história cultural de Rosário ou da Argentina.

Embora disponha-se de documentação sobre o que aconteceu durante a ditadura, a verdade é que muito mais energia e tempo foram dedicados a descobrir o que se passou nas prisões clandestinas do que a documentar encontros secretos entre adolescentes rebeldes ou intelectuais assustados. Não houve arqueólogos forenses enviados a Rosário para investigar as atividades de grupos obscuros de teatro, embora alguns investigadores tenham, sim, ido. Somente quando esse outro corpo de conhecimento tenha sido reconstruído adequadamente - quem foi morto? como, quando e por quem? todas essas perguntas que ainda fazem parte da vida argentina - será possível fazer perguntas mais específicas sobre as atividades dos sobreviventes. Somente então, e talvez este então seja agora, será possível investigar o período da ditadura do ponto de vista do que foi feito e não do que foi destruído. Mesmo então, e isso talvez seja agora, a história do Teatro Cucaño será uma história difícil de reconstruir.

Existem alguns vestígios de sua existência. Mas a maioria dos materiais sobreviventes foi coletada de maneira não sistemática por membros do grupo, dispersa entre eles, abandonada em porões e armários. Muitos anos após o fim não oficial do grupo, em 1983, alguns membros fundadores se encontraram em Rosário para conversar sobre o que haviam feito quando tinham quinze, dezesseis e dezessete anos. Gravaram suas conversas, esperando que a gravação tivesse uma vida mais longa do que o trabalho que fizeram na época. Queriam retificar, pelo menos parcialmente, a ausência de documentos que certificassem quem eles eram e o que haviam feito. Na conversa, Carlos Ghioldi, Guillermo Giamprieto, Mariano Guzmán e Osvaldo Aguirre contaram suas diferentes versões do que acontecera, mas o exercício parecia nada mais que uma série de anedotas misturadas com o ruído de fundo de alguns meninos brincando nas proximidades.

O desejo de documentar retrospectivamente o que eles fizeram fala tanto da natureza efêmera do grupo quanto de sua longevidade mítica. Hoje, muitos ex-membros consideram o Teatro Cucaño como sua experiência formativa. Ghioldi, que trabalha como ativista e administra um centro cultural e um mercado coletivo, é pálido e magro. Ainda se parece com o que dizem que parecia aos quinze: um anjo morto. Mariano Guzmán, músico e artista independente, mantém um site que, entre outras coisas, registra a história do Teatro Cucaño e a sua produção. Após a ditadura, Guzmán foi um dos poucos cucaños que tentou manter o grupo ativo, embora a maioria de seus participantes tenha perdido o interesse quando se tornou possível ser politicamente ativo 
abertamente. Guzmán continuou planejando intervenções: invadiu um dos cafés literários de Rosário em 1984, vestido de nazista e brandindo um rifle falso. Osvaldo Aguirre, um homem pequeno que era o mais jovem cucaño, é hoje jornalista em Rosário e poeta de sucesso. Em 1998, escreveu um artigo no principal jornal rosarino sobre essa experiência. Entre os jovens que atualmente vivem em Rosário, o Teatro Cucaño é algo que eles conhecem pelo nome, mesmo quando esse conhecimento é vago. Como ativista local em uma pequena comunidade, Ghioldi é conhecido como o fundador do Teatro Cucaño. Um grupo de jovens escritores de Rosário dedicou recentemente uma série da revista Señal Hoguera para reconstruir a história do grupo.

Mas, em geral, o Teatro Cucaño segue sendo desconhecido. Não ocupa um lugar na memória pública da ditadura; é, porém, relegado a uma invisibilidade ainda maior do que a de outros projetos culturais relativamente obscuros da época. Não existe uma biblioteca que coleciona os materiais do grupo, nem referências a ele nos poucos livros que tratam da arte de vanguarda em Rosário ou na Argentina. Nunca é mencionado nos muitos estudos que existem acerca do teatro argentino durante o período ditatorial. Foi por acaso, sorte e a generosidade de estranhos que eu, pesquisadora estrangeira, fazendo perguntas sobre atividades culturais obscuras nos rincões mais ocultos durante os períodos mais sombrios, encontrei o Teatro Cucaño. Seus restos e sua história residem nos recessos da biblioteca vaginal onde foram criados, uma biblioteca onde o conteúdo corre o risco de se desintegrar constantemente, onde poucos sabem o que e como procurar. É uma biblioteca que não existe.

\section{Referências bibliográficas}

BARTHES, Roland. Fragmentos de um discurso amoroso. Tradução de Márcia Valéria Martinez de Aguiar. São Paulo: Martins Fontes, 2003.

BENJAMIN, Walter. O narrador. In: Magia e técnica, arte e politica - ensaios sobre literatura e história da cultura. Obras escolhidas. Tradução Sérgio Paulo Rouanet. 2a edição. São Paulo: Editora Brasiliense, 1994, volume I.

BRoCATO, Carlos. El exilio es el nuestro. Buenos Aires: Sudamericana; Planeta, 1986.

CuAdernos del CAMino, n. 2, 1980.

DERRIDA, Jacques. Mal de arquivo: uma impressão freudiana. Tradução de Claudia de Moraes Rego. Rio de Janeiro: Relume Dumará, 2001.

GALEANO, Eduardo. Crisis, o cómo matar una revista, em Argentina: cómo matar la cultura, Madrid: Revolución, 1981.

GHIOLDI, Carlos. Carta a Compañeros del TIT. Arquivo Teatro Cucaño do CeDinCi, 14 may. 1982.

TARCUS, Horacio; ZATTARA, Enrique. Hacia una gran revista cultural independiente. Nova Arte, n. 6, 1980. 